\title{
DO PORTO AO PRÉ-SAL: SUSTENTABILIDADE URBANA NA BAIXADA SANTISTA PORT TO PRE-SALT: URBAN SUSTAINABILITY IN SANTISTA BAIXADA
}

\section{Elizabeth Borelli ${ }^{1}$}

\section{Resumo:}

Este artigo se propõe a investigar aspectos sociais, econômicos e ambientais importantes para a compreensão da nova realidade da Região Metropolitana da Baixada Santista, tendo por objetivo propor uma reflexão inicial em termos da problemática da sustentabilidade urbana. Essa preocupação se justifica pela nova configuração do mercado regional que se vislumbra, com a descoberta de petróleo e gás, na Bacia de Santos, e com a escolha do local para abrigar a sede administrativa da Unidade de Negócios de exploração e produção da Petrobrás, no Estado de São Paulo, o que deverá alterar sensivelmente a matriz econômica da região, tradicionalmente voltada ao turismo e às atividades portuárias, com relevantes repercussões sobre a questão urbana.

Palavras-chave: sustentabilidade urbana - região metropolitana - transformações urbanas.

\section{Abstract:}

This article aims to investigate important for understanding the new reality of the metropolitan area of Santos, aiming to propose an initial reflection in terms of the problem of urban sustainability social, economic and environmental aspects. This concern is justified by the new configuration of the regional market in sight, with the discovery of oil and gas in the Santos Basin, and the choice of where to house the administrative headquarters of the Business Unit Petrobras exploration and production in State of Sao Paulo, which should substantially change the economic matrix of the region traditionally geared towards tourism and port activities, with significant impact on the urban question.

Keywords: urban sustainability - metropolitan area - urban transformations

\footnotetext{
${ }^{1}$ Pós-doutorado em Ciências Sociais (CLACSO). Professora do Programa de Estudos Pós-graduados
} em Economia Política da PUCSP e Coordenadora do Curso de Ciências Atuariais (FEA - PUCSP). E-mail: eborelli@pucsp.br 


\section{INTRODUÇÃO}

A proposta deste artigo tem por escopo as relações de transformações urbanas e econômicas da região administrativa da Baixada Santista, em torno da questão da sustentabilidade.

Hoje, a polarização da cidade de Santos em relação aos demais municípios é indiscutível e a economia regional reforça o seu papel central nessa área metropolitana.

Nos últimos anos, o crescimento urbano da região ganhou novo impulso. A divulgação da descoberta do petróleo na Bacia de Tupis, pela Petrobrás, em 2007, na chamada camada Pré Sal1- área localizada entre os Estados de Santa Catarina e Espírito Santo - atraiu novos investimentos imobiliários e de negócios para a região.

E assim, em janeiro de 2006, a Petrobrás inaugurou a sua sede em Santos, para gerenciar a área de produção de petróleo na Bacia do Pré-Sal. Foi anunciado um investimento de cerca de U\$ 73 bilhões até 2015 na cidade, com a implantação do Plansal - Plano Diretor de Desenvolvimento Integrado do Polo Pré-Sal da Bacia de Santos - que prevê a construção da sede da empresa em bairro do centro histórico da cidade, próximo ao Porto, que vem sendo cenário de grandes transformações urbanas.

Esses novos investimentos, particularmente no setor imobiliário no município de Santos, estão transformando a paisagem e alterando o modo de vida da cidade. Observa-se, no município de Santos, um notório crescimento de novos empreendimentos imobiliários, com características bem diferentes das que existiam até então, como áreas de lazer internas nos edifícios, apartamentos compactos e funcionais, empreendimentos com funções comerciais e residenciais, aumento do número de vagas por unidade habitacional e, com maior destaque, grande crescimento do número de pavimentos nos edifícios, fortalecendo o processo de verticalização.

A partir destes fatos, a proposta que norteia esta reflexão é indagar até que ponto a região está preparada, do ponto de vista da sustentabilidade, para enfrentar as transformações urbanas inerentes à mudança na sua forma de inserção no grande capital. Para tanto, o referencial teórico será pautado no conceito de sustentabilidade urbana, procurando identificar as diversas visões sobre o tema. Em seguida, serão apresentadas informações institucionais sobre as questões de região administrativa e política pública de saneamento. Serão então levantados aspectos demográficos, econômicos e de infraestrutura, na tentativa de se delinear um perfil das condições socioeconômicas da região da Baixada Santista, à luz do processo de transformações urbanas. 
Para a pesquisa que embasou este artigo, foi adotada a metodologia de análise exploratória, para uma identificação de fatos e vertentes, em torno da literatura referente a sustentabilidade e urbanização, e consultada a documentação oficial existente.

\section{SUSTENTABILIDADE URBANA E DINÂMICA SOCIOECONÔMICA}

O conceito de sustentabilidade urbana, ao longo da década de 1990, consolidou a convergência da questão ambiental e da questão urbana, ou seja, da oposição entre o natural e o não-natural. Essa nova conceitualização surge com a mudança do enfoque do ambientalismo, que passou de uma vertente preservacionista e conservacionista, em sua origem, para a temática da sustentabilidade, nos anos 1980.

Assim, as questões vinculadas a desenvolvimento urbano, controle da poluição atmosférica e hídrica nas cidades, e ainda, à utilização sustentável de recursos naturais - e conservação de espaços verdes no interior dos espaços urbanos - ganharam relevo na agenda das principais organizações multilaterais, voltadas para o desenvolvimento e para a questão urbana na década de 1990, bem como nos critérios para aprovação de projetos e concessão de financiamentos (BRAGA, 2006).

No âmbito das Conferências Internacionais, a questão ambiental no espaço urbano foi incluída como um dos cinco grandes temas do Hábitat $\mathrm{II}^{2}$, e discutida na Conferência Rio $92^{3}$, tendo seus pontos principais sistematizados na Agenda 21, que elegeu o tema cidades sustentáveis como um dos seis pilares de construção da sustentabilidade ambiental, social e econômica dos países. (NOVAES, 2000).

Acselrad (1999) define a sustentabilidade urbana como a capacidade das políticas urbanas em se adaptarem à oferta de serviços, à qualidade e à quantidade das demandas sociais, buscando o equilíbrio entre as demandas de serviços urbanos em investimentos em estrutura. Considera, também, imprescindível para a sustentabilidade urbana, o uso racional dos recursos naturais, além das respostas às necessidades urbanas com o mínimo de transferência de dejetos e rejeitos para outros ecossistemas atuais e futuros.

\footnotetext{
${ }^{2}$ Conferência internacional da ONU sobre as cidades.

${ }^{3}$ Conferência internacional da ONU sobre meio ambiente e desenvolvimento.
} 
Ele investiga os diversos discursos sobre a sustentabilidade urbana e identifica três matrizes. A primeira, a que chamou de representação tecnomaterial da cidade, combina modelos de racionalidade energética com modelos de equilíbrio metabólico e reduz a sustentabilidade urbana a seu aspecto estritamente material. A segunda, conceituada como representação da cidade como espaço da qualidade de vida, combina modelos de pureza, de cidadania e de patrimônio e remete a sustentabilidade a um processo de construção de direitos, que possam equacionar as externalidades negativas, responsáveis pela insustentabilidade urbana. A terceira matriz centra-se na reconstituição da legitimidade das políticas urbanas, combinando modelos de eficiência e equidade, e remete a sustentabilidade à construção de pactos políticos capazes de reproduzir suas próprias condições de legitimidade. (ACSELRAD, 1999).

Em consonância com essa terceira matriz, o Urban World Forum (2002) define sustentabilidade urbana a partir de um conjunto de prioridades, tais como: superar a pobreza, promover a equidade, melhorar a segurança ambiental e prevenir a degradação. (BRAGA, 2006).

Por outro lado, para ser considerada sustentável, não é suficiente que uma cidade confira aos seus habitantes, condições ambientais equilibradas, mas é necessário que isso ocorra sem gerar externalidades negativas para outras regiões e para as gerações futuras. (MCGRANAHAN e SATTERTHWAITE, 2002; MILLER e SMALL, 2003).

Nessa perspectiva, considera-se a escala regional - constituída pela cidade e suas relações com o entorno - e a escala global - constituída pelos seus impactos sobre os problemas ambientais globais, bem como por questões relativas aos impactos agregados da rede mundial de grandes cidades.

Contudo, observa-se grande dificuldade de sistematização de informações para a gestão ambiental urbana. A partir disso, desde o final da década de 1980, vêm surgindo diversas iniciativas de construção de índices e indicadores, quase sempre aplicados à escala nacional, com o objetivo de fornecer subsídios à formulação de políticas e acompanhar a implementação de acordos internacionais.

No seu conteúdo, procuram descrever e mensurar a interação entre a atividade antrópica e o meio ambiente, conferindo à ideia de sustentabilidade, uma maior operacionalidade e funcionalidade.

No Brasil, destaca-se o trabalho: Indicadores de Desenvolvimento Sustentável- Brasil 2004, do IBGE - Instituto Brasileiro de Geografia e Estatística - que calcula indicadores de 
sustentabilidade nas dimensões ambiental, social, econômica e institucional para os Estados brasileiros (IBGE, 2004).

Para a construção de medidas de sustentabilidade urbana são incluídos índices tradicionais, como o Produto Interno Bruto (PIB) e o Índice de Desenvolvimento Humano (IDHM); considere-se, ainda, a inexistência de consenso em relação aos conceitos de sustentabilidade e de qualidade ambiental, o que dificulta o processo de escolha de variáveis para a composição dos indicadores urbanos de sustentabilidade (ENVIRONMENTAL SUSTAINABILITY INDICATORS, 2002).

Para Rogers e Gumuchdjian (2001), o processo de expansão das cidades não tem considerado a fragilidade do ecossistema, evidenciando seu caráter predominantemente quantitativo - associado à ideia de "modernização" - em detrimento do aspecto qualidade, registrando-se, no mundo, um aumento global de riqueza, paralelamente ao aumento do grau de pobreza e da população pobre. Consideram, ainda, que a problemática urbana assume diferentes contornos, conforme o nível de industrialização de cada país. Nos países em desenvolvimento, os problemas ambientais e sociais são agravados pelo aumento do tamanho das cidades sem o acompanhamento de infraestruturas capazes de suportar tal crescimento. Em todo o mundo, a pobreza ainda é um dos principais problemas enfrentados pelas sociedades, e, geralmente, a camada mais pobre da população é amplamente negligenciada. Diante disso, torna-se necessário um desenvolvimento urbano sustentável, diferente do modelo atual, que é baseado no lucro e privilegia uma pequena parte da sociedade.

Diversos autores vêm discutindo acerca de uma base teórica da interdependência entre as trajetórias do desenvolvimento urbano regional e as políticas territoriais em suas diversas dimensões. A teoria da regulação (BOYER, 1990; BENKO, 1996) e a teoria do urbanismo industrial (SCOTT, 1998; STORPER, 1997) enfatizaram a transição dos regimes fordistas para os pós-fordistas de acumulação e regulação, bem como suas implicações territoriais, enquanto Harvey (1989) analisou a mudança dos regimes urbanos gerenciais para um estilo empresarial de governança. Swyngedouw (1997) enfocou as dimensões escalares desse debate e elaborou o conceito de glocalização, visando destacar a natureza política interdependente das escalas territoriais de poder.

Brenner (2004) fundamentou a reestruturação produtiva e territorial em uma análise mais geral sobre a transformação dos "regimes de políticas públicas territoriais", a partir da década de 1970. Seu principal argumento é que, a partir desse período, o regime keynesiano de organização e intervenção do Estado na produção do espaço, composto por projetos e estratégias, evoluiu para 
um regime competitivo e reescalonado de organização e intervenção territorial do Estado. Nessa ótica, projetos significam a organização administrativa interna das políticas públicas territoriais, enquanto as estratégias seriam as intervenções efetivas do Estado na produção do espaço, especialmente através de programas de investimento e modelos de regulação.

Ainda que a pobreza medida por indicadores nacionais diminua com a urbanização, de um modo geral, o número absoluto de moradores de favelas aumenta mais do que o crescimento da população urbana (Un-Habitat, 2010). A concentração de pobres em gigantescas favelas - que contam com domicílios congestionados e insalubres, sem água potável, sem esgotos, sem coleta de lixo - com baixa taxa de emprego, com elevados índices de violência, representa um aspecto qualitativo que caracteriza a pobreza urbana.

Em relação às cidades brasileiras, Maricato (2011), pontua que sua imagem está drasticamente associada à violência, à poluição, ao tráfego caótico, às enchentes, à desigualdade social, entre outros pontos de caracterização urbana e destaca a importância do Sistema Financeiro Habitacional nesse processo.

O Sistema Financeiro da Habitação (SFH) e seu gestor, o Banco Nacional da Habitação (BNH), foram, na verdade, os organismos que mais impactaram o crescimento e o padrão de urbanização brasileira, disseminando o apartamento de classe média, fortalecendo os negócios de incorporação imobiliária e a indústria da construção. Com a habitação social localizada fora do tecido urbano, de um modo geral, o BNH e seu sistema financeiro não só contribuíram para segregar as camadas sociais de menor renda, como impediram o mercado de terras urbanas, potencializado pelos recursos do financiamento residencial oriundos da poupança privada (Sistema Brasileiro de Poupança e Empréstimo - SBPE) e da poupança compulsória (Fundo de Garantia por Tempo de Serviço - FGTS), de operar de forma sustentável. (MARICATO, 2011,11).

Em sua colocação, as transformações capitalistas, orientadas pelo pensamento neoliberal (no Brasil, em 1980, 1990 e 2000), tiveram forte impacto sobre as cidades. A falta de regulamentação do mercado imobiliário, o desemprego, a competitividade, a guerra fiscal, o abandono de políticas sociais, como o transporte coletivo, as privatizações de serviços públicos, o planejamento estratégico, o marketing urbano, entre outros, se uniu a uma tradição histórica de falta de controle sobre o uso do solo e de segregação territorial e urbana.

A violência nas metrópoles se evidencia pelo aumento da taxa de homicídios, nesse período, de forma inédita. Tragédias provocadas por enchentes e desmoronamentos tornam-se, progressivamente, mais frequentes. (SALDIVA et al., 2010). A ocupação irregular de beira de 
córregos, encostas desmatadas, mangues, dunas e áreas de proteção de mananciais mostram a precariedade das condições de vida de uma grande parcela da população.

No âmbito das políticas socioeconômicas brasileiras, foram implementados, mais recentemente, programas dirigidos à população mais miserável, com o objetivo de retirá-la do nível de subsistência precário em que se encontravam, através de programas de transferência de renda (Bolsa Família) e de um conjunto de políticas sociais destinadas a aumentar as oportunidades de empreendedorismo e desenvolvimento econômico (ALMEIDA, 2005).

Por outro lado, cabe destacar a retomada do papel dos bancos e fundos públicos na provisão de crédito e na alavancagem dos investimentos públicos e privados, através de programas como o PAC - Programa de Aceleração do Crescimento, Minha Casa, Minha Vida e o fomento a outros setores econômicos específicos. (SANT'ANNA, BORÇA Jr \& ARAUJO, 2009).

Do ponto de vista institucional, foram verificados avanços no campo do Direito à Moradia e Direito à Cidade, a partir da incorporação à Constituição, em 1988, de um capítulo de política urbana, estruturado em torno da noção de função social da cidade e da propriedade, do reconhecimento dos direitos de posse de milhões de moradores das favelas e periferias das cidades do país e da incorporação direta dos cidadãos aos processos decisórios sobre esta política. O boom da construção civil reflete os sinais do crescimento econômico, ganhando visibilidade em diversas cidades e metrópoles brasileiras. (ROLNIK, 2010).

As dinâmicas econômicas recentes vêm oferecendo um desafio às cidades, no sentido de converter este crescimento em melhoria nas condições de urbanização, não apenas em termos de expansão da infraestrutura das cidades para absorver um crescimento futuro, mas, sobretudo, de mudança do modelo financeiro e de gestão sobre a qual se constituiu o processo de urbanização, marcado por disparidades socioespaciais e grande degradação ambiental. Apesar dos ganhos da política econômica e do Estatuto das Cidades, as marcas deste modelo continuam presentes em várias dimensões do processo de urbanização. (ROLNIK 2010).

O padrão de investimentos em obras metropolitanas mostra a falta de integração entre as ações de cada município que compõe as metrópoles. Macrodrenagem, coleta e distribuição de água tratada, coleta e tratamento de esgoto, habitação, uso e ocupação do solo, transporte de cargas e passageiros, são temas que exigem um tratamento integrado na metrópole.

\section{REGIÕES METROPOLITANAS E POLÍTICA DE SANEAMENTO}


Há uma opinião generalizada, expressa em vários estudos acadêmicos e técnicos, acerca da precariedade do quadro legal de Regiões Metropolitanas (RM) no Brasil, advindos da diversidade de critérios - convencionados em cada Estado, após a Constituição Federal de 1988. As trinta e cinco Regiões Metropolitanas, definidas legalmente em 2010, às quais se somam três Regiões Integradas de Desenvolvimento Econômico (Rides) que abrangem mais de um Estado, constituem um conjunto heterogêneo, dentro do qual figuram aglomerações urbanas com importância demográfica, econômica, social e política bastante diferenciada.

Na Baixada Santista, o processo de urbanização gerou a fusão de núcleos urbanos, transformando-a em região metropolitana, com a cidade de Santos incorporando núcleos vizinhos e estabelecendo com eles, relações correspondentes a um único núcleo urbano de grandes proporções. (REIS FILHO, 1987).

Do ponto de vista urbanístico, a região é densamente urbanizada na faixa mais próxima do mar, possuindo áreas de preservação de Mata Atlântica nos trechos mais próximos à serra e em suas escarpas. Como unidade espacial, em função de suas características políticas, socioeconômicas e urbanísticas, veio a se constituir na segunda Região Metropolitana do Estado de São Paulo.

Nesse processo de conurbação, tanto os bairros nobres como os populares ultrapassam os limites político-administrativos de seu município e ocupam áreas dos municípios vizinhos, polarizados pelo centro urbano mais importante.

No processo de urbanização da Baixada Santista, as atividades urbanas - industriais, portuárias, comerciais e residenciais- têm gerado efeitos negativos no sistema natural, descaracterizando ou mesmo eliminando ecossistemas terrestres e estuarinos e comprometendo os processos naturais. A condição de elevada poluição das águas, devido aos efluentes e resíduos urbanos, tem provocado mudanças na diversidade biológica, agravando a condição natural de estresse típica dos estuários. (AFONSO, 2006).

Genericamente, a causa mais frequente de degradação das águas costeiras próximas às praias é a poluição por esgotos domésticos. A expansão urbana vem provocando condições inadequadas de balneabilidade das praias, uma vez que não há sistemas adequados de coleta e tratamento dos esgotos. Observa-se a ocorrência de lançamentos de esgotos clandestinos nas galerias de águas pluviais, canais e córregos, com a afluência de grande quantidade de dejetos no mar. A Baixada Santista apresenta similaridades com esse cenário, com exceção do município de Santos, que conta com, praticamente, a totalidade dos domicílios ligada à rede coletora de 
esgotos. Nos demais municípios da região, menos da metade da população conta com esse serviço público, com córregos, canais e galerias de águas pluviais recebendo esgotos clandestinos. (CETESB, 2012).

Por outro lado, a temática do saneamento básico surgiu em decorrência do grande processo de urbanização e desenvolvimento das cidades, quando suas estruturas habitacionais, terrenos, prestações de serviços à comunidade e emprego passaram a configurar problemas socioambientais. Com a edição da Lei no 11.445/07, saneamento básico foi conceituado como o conjunto de serviços, infraestruturas e instalações de abastecimento de água, esgotamento sanitário, limpeza urbana e manejo de resíduos sólidos e drenagem de águas pluviais urbanas.

O modelo de gestão de saneamento revela a predominância da gestão por Companhias Estaduais; dos municípios que integram regiões metropolitanas, em aproximadamente $77 \%$ destes, a responsabilidade é de um prestador regional - as companhias estaduais de saneamento (CESBs). Em 20\% dos municípios, o serviço é prestado por uma empresa local de direito público, e o restante é dividido entre empresas de abrangência local de direito privado e empresas estritamente privadas.

Segundo o Sistema Nacional de Informações sobre Saneamento, as regiões metropolitanas são responsáveis por um mercado de aproximadamente $\mathrm{R} \$ 20,76$ bilhões, restando aos demais municípios brasileiros uma receita operacional total de $\mathrm{R} \$ 11,08$ bilhões. O mercado metropolitano corresponde a aproximadamente $65 \%$ do total brasileiro, sendo deste total $65 \%$ concentrados nos municípios núcleos das metrópoles. (SNIS, 2010). Estes dados atestam a predominância de uma gestão metropolitana do saneamento.

O Plano Nacional de Saneamento Básico (Plansab), aprovado pelo Conselho Nacional das Cidades (Concidades) em Junho de 2013, prevê um investimento de $\mathrm{R} \$ 508,5$ bilhões em obras de abastecimento de água potável, coleta e tratamento de esgoto e lixo e em ações de drenagem, entre 2014 e 2030. O Plano orienta o planejamento para os próximos 20 anos, e projeta que serão investidos entre $\mathrm{R} \$ 10$ bilhões e $\mathrm{R} \$ 12$ bilhões por ano, até 2030. O documento é dividido em uma série de metas de curto, médio e longo prazos - para 2018, 2023 e 2030 - e inclui as respectivas estratégias, ações e recursos considerados necessários. As metas foram definidas a partir da evolução histórica e da situação atual dos indicadores de cobertura destes serviços, com base na análise situacional do déficit em todo o país. (MINISTÉRIO DAS CIDADES, 2013).

A proposta expressa que esse documento sirva como um guia para os gestores, com diretrizes e estratégias, metas, resultados esperados e programas de investimentos. A 
implementação requer a atuação integrada do governo federal, estados e municípios, além de todos os agentes públicos e privados, sob a coordenação do Ministério das Cidades. Com isso, se anuncia uma nova forma de gestão para a questão do saneamento, rompendo com o mecanismo de centralização que, até agora, vem caracterizando esta política. Para o abastecimento de água potável, o Plansab prevê a universalização nas áreas urbanas no decorrer dos próximos dez anos; para as ações de coleta e tratamento de esgoto, a meta é atender 93\% das áreas urbanas, no período de vinte anos.

O documento coloca, ainda, como objetivo, extinguir os esgotos sem tratamento - de forma a não ser mais permitido o escoamento de esgotos no meio ambiente, visando diminuir a contaminação de rios e córregos. O Plano Nacional de Saneamento Básico determina, também, a extinção dos lixões, a partir de 2014, já que, além de contaminar e degradar muitas áreas ambientais, também colaboram para a proliferação de doenças, implicando na necessidade de se pesquisar novos processos de condução dos resíduos para aterros sanitários. (MINISTÉRIO DAS CIDADES, 2013).

As políticas públicas voltadas para a melhoria das condições de saneamento básico das comunidades são eficazes para diminuir a mortalidade infantil pós-neonatal, período este em que os óbitos ocorrem, principalmente, devido a doenças relacionadas às condições ambientais. Esse fato confirma que o aumento da cobertura populacional por sistemas de esgotamento sanitário, pode contribuir para reduzir a mortalidade infantil no Brasil (HOLCMAN, LATORRE e SANTOS, 2004).

Neste contexto, evidenciam-se os efeitos positivos do saneamento no crescimento econômico e na redução da pobreza. Segundo um estudo da Organização Mundial da Saúde, cada dólar investido na melhoria do saneamento para o alcance dos Objetivos de Desenvolvimento do Milênio gera, em média, um benefício econômico de US\$ 12 (PRÜSS-ÜSTÜN et al., 2008).

As deficiências de saneamento redundam em prejuízos à saúde, reduzem a produtividade do trabalho e impactam a atividade econômica. A investigação dos reflexos econômicos da ausência de saneamento básico revela, no entanto, uma consequência relacionada à qualidade da ocupação urbana. Portanto, o saneamento qualifica o solo urbano, pois possibilita construções de maior valor agregado e a valorização de construções existentes, o que implica no aumento do capital imobiliário das cidades. Contudo, as famílias de mais baixa renda são as que mais sofrem com problemas de saneamento, em especial com a falta de coleta de esgoto. Dessa forma, avanços 
na qualificação do espaço urbano em razão de investimento em infraestrutura de saneamento implicam em valorização no capital residencial, inclusive, para as famílias de baixa renda.

\section{CARACTERIZAÇÃO REGIONAL DA BAIXADA SANTISTA}

A Região Metropolitana da Baixada Santista - RMBS - localizada na porção central do litoral do Estado de São Paulo, foi criada em 1996 por um decreto estadual, abrangendo áreas insulares e continentais, sendo composta por nove Municípios: Bertioga, Cubatão, Guarujá, Itanhaém, Mongaguá, Peruíbe, Praia Grande, Santos e São Vicente.

As tendências demográficas da Baixada Santista podem ser analisadas sob a ótica da teoria da polarização, de Perroux (1950), como referência, que segmenta a organização regional a partir da cidade-polo, sendo, portanto, perfeitamente aplicável às regiões metropolitanas. A cidade-polo possui como característica principal as forças de atração para novos investimentos, em função de seu histórico e de atividades econômicas consolidadas; em contrapartida, apresenta os espaços de repulsão - ou seja, aqueles que incluem atividades incompatíveis com suas características originais e desenvolvidas ao longo dos anos.

Adaptando esta teoria ao caso da RMBS, Santos será considerada a cidade-polo. Para este município, importa considerar a abordagem a partir de sua área insular, uma vez que o índice populacional da área continental é pouco significativo. A área insular de Santos conta com apenas $39 \mathrm{~km}^{2}$, onde vivem mais de 95\% da população municipal. (VAZQUEZ e VAZ, 2012).

A expansão imobiliária ocorrida entre os anos de 1960 e 1970, em função de importantes fatores, tais como, a acessibilidade pelas rodovias Anchieta e Imigrantes, o crescimento das atividades turísticas e a influência do polo industrial de Cubatão, transformaram a paisagem e conduziram um processo de urbanização desordenado. Mesmo com a criação da RMBS, em 1996, os municípios continuam pouco integrados, especialmente na questão do trânsito. (VAZQUEZ e VAZ, 2012).

A região apresenta um recorte regional com características especiais, condicionadas por obstáculos geográficos significativos, apresentando áreas de urbanização continental e insular e uma malha urbana bastante densa.

A região é fortemente influenciada pela dinâmica econômica e social do Porto de Santos, que se constitui, desde a origem da urbanização regional, no fator principal do desenvolvimento dos processos de urbanização. 
A presença de um polo energético, petroquímico, siderúrgico e industrial de grande porte no município de Cubatão também foi fator importante no desenvolvimento regional, contribuindo para atrair grande contingente populacional.

Em termos de especulação e de valorização imobiliária, verifica-se uma situação diferenciada de processos que podem ser colocados como especiais, por serem ocasionados pela existência de um mercado imobiliário turístico altamente desenvolvido e sua intensa utilização, pelo fenômeno da segunda residência. Além do aspecto imobiliário e dos processos econômicos, verifica-se, no caso das regiões metropolitanas em geral, e especialmente no da Baixada Santista, que a conurbação das áreas urbanas dos vários municípios que a compõem é grande e bastante significativa. A existência da conurbação não chega a ser considerada um fato extraordinário, pois é uma exigência constitucional e legal da Constituição do Estado, para a implementação do recorte institucional denominado Região Metropolitana.

No caso da RMBS, aliados ao alto grau de conurbação das cidades, existem ainda uma gama de fatores limitadores de ordem física, geológica, geográfica e ambiental, que facilitaram a implantação do processo de mobilidade populacional e da alteração do uso e ocupação do solo. A região apresenta cerca de 65 km contínuos de extensão litorânea, com cerca de 122 praias.

Em relação à acessibilidade à região, no modo ferroviário, dá-se por meio da utilização de duas malhas ferroviária distintas - a antiga malha da Rede Ferroviária Federal S.A., atualmente concessionada à empresa MRS Logística S.A., e pelo antigo acesso das Ferrovias Paulista S.A. Fepasa, atualmente concessionado à empresa Ferrovia dos Bandeirantes S.A. - Ferroban.

Os acessos rodoviários são feitos entre sua parte mais central e a Região Metropolitana de São Paulo - RMSP, através da Rodovia Anchieta (SP 150), Rodovia dos Imigrantes (SP 160) - por onde ocorre o maior volume de tráfego, pela Rodovia Dom Paulo Rolim Loureiro (MogiBertioga/SP 098), ligando a região à RMSP e ao vale do Rio Paraíba do Sul, pela Rodovia Prestes Maia (Rio-Santos/SP 055), fazendo a ligação entre a RMBS e o litoral norte e a Padre Manoel da Nóbrega (SP 055), ligando a região com o litoral sul e o vale do rio Ribeira do Iguape.

O município de Santos caracteriza-se como polo regional, porém, em função de sua limitação geográfica e pelo fato de ser um município basicamente insular, pois sua área continental é pouco ocupada e utilizada, o município exerce influência em toda a região, pois concentra, além da maior parte das instituições estaduais e federais, a maior população, comércio e serviços. 
A influência da cidade é exercida, inclusive, em relação aos municípios próximos, mas situados fora dos limites da região metropolitana, como no caso dos litorais sul e norte, o que o caracteriza como um polo supra-regional.

A área de influência é mais forte e sentida nos municípios mais próximos, na região conformada pela aglomeração dos municípios de São Vicente, Guarujá, Cubatão e Praia Grande, onde o primeiro tem sua sede localizada na ilha de São Vicente; o segundo, na ilha de Santo Amaro, e os demais estão localizadas em áreas continentais.

Numa área de mais de $2 \mathrm{mil} \mathrm{km}^{2}$, vivem cerca de 1,8 milhão de habitantes, segundo dados do Censo Demográfico do IBGE de 2010 - número esse que atinge, praticamente, o dobro, no período de temporada de férias. Os turistas concentram-se em certos municípios, com grande destaque para Praia Grande e Guarujá e em menor quantidade nos municípios de Peruíbe, Bertioga, Itanhaém e Mongaguá.

Os municípios de Santos e São Vicente, apesar de apresentarem incrementos populacionais muito pequenos, entre os Censos Demográficos de 2000 e 2010, são os municípios que apresentam os maiores dados de populações residentes, como pode ser observado na Tabela 1.

As maiores taxas de incremento populacional estão nos municípios de menor população residente, como Bertioga e Mongaguá, enquanto nos municípios com população superior, a taxa de incremento é pequena, como Santos, São Vicente e Cubatão. Esses três municípios apresentam inclusive, como pode ser observado na Tabela 1, uma taxa de incremento populacional inferior à média da região metropolitana.

Ainda no caso do município de Santos, sua taxa de incremento populacional é inferior à média do Estado de São Paulo, chegando, na década de 1990, a apresentar, em determinados anos, uma taxa negativa de crescimento populacional. 


\begin{tabular}{|c|c|c|c|c|c|}
\hline \multirow[t]{2}{*}{$\begin{array}{l}\text { Regiões e } \\
\text { Municípios }\end{array}$} & \multicolumn{3}{|c|}{ População } & \multicolumn{2}{|c|}{$\begin{array}{c}\text { Taxas anuais de crescimento } \\
\text { Populacional (\%) }\end{array}$} \\
\hline & 1991 & 2000 & 2010 & $1991 / 2000$ & $2000 / 2010$ \\
\hline $\begin{array}{c}\text { Estado de } \\
\text { SP }\end{array}$ & 31.436 .273 & 36.974 .378 & 41.223 .683 & 1,82 & 1,09 \\
\hline RMSP & 15.369 .205 & 17.852 .637 & 19.667 .558 & 1,68 & 0,97 \\
\hline RMBS & 1.214 .980 & 1.473 .912 & 1.662 .392 & 2,17 & 1,21 \\
\hline Bertioga & 11.307 & 29.771 & 47.462 & 11,36 & 4,77 \\
\hline Cubatão & 90.866 & 108.135 & 118.629 & 1,95 & 0,93 \\
\hline Guarujá & 208.818 & 264.235 & 290.526 & 2,65 & 0,95 \\
\hline Itanhaém & 45.619 & 71.694 & 86.919 & 5,15 & 1,94 \\
\hline Mongaguá & 18.781 & 34.897 & 46.186 & 7,13 & 2,84 \\
\hline Peruíbe & 32.676 & 51.237 & 59.698 & 5,13 & 1,54 \\
\hline $\begin{array}{l}\text { Praia } \\
\text { Grande }\end{array}$ & 122.354 & 192.769 & 261.391 & 5,18 & 3,09 \\
\hline Santos & 417.114 & 417.975 & 419.388 & 0,02 & 0,03 \\
\hline $\begin{array}{c}\text { São } \\
\text { Vicente }\end{array}$ & 267.445 & 303.199 & 332.193 & 1,40 & 0,92 \\
\hline
\end{tabular}

Fonte: IBGE. Censo demográfico / SEADE (2010).

A densidade demográfica destes municípios é outro dado que merece atenção: os municípios de Guarujá, Santos, São Vicente e Praia Grande apresentam uma elevada densidade demográfica, com respectivamente 1851 hab. $/ \mathrm{km}^{2}, 1488$ hab. $/ \mathrm{km}^{2}, 2089$ hab. $/ \mathrm{km}^{2}$ e 1345 hab./km². (JAKOB ,2003).

Essas elevadas densidades demográficas indicam um aspecto peculiar da urbanização dessas áreas: a elevada concentração urbana e a falta de espaços livres na área urbana desses municípios 
A partir destes dados, constata-se que, desde 1980, Santos já estava com sua população consolidada em virtude "da estagnação da população, da elevada densidade e da preservação da área continental como reserva natural". (VAZQUEZ, 2012, p. 271).

\begin{tabular}{|c|c|c|c|c|}
\hline \multicolumn{5}{|c|}{ Tabela 2: Saldos migratórios e taxas anuais de migração, 1991/2010 } \\
\hline \multirow[t]{2}{*}{$\begin{array}{l}\text { Regiões e } \\
\text { Municípios }\end{array}$} & \multicolumn{2}{|c|}{ Saldos Migratórios Anuais } & \multicolumn{2}{|c|}{$\begin{array}{c}\text { Taxas anuais de migração (por } 1000 \\
\text { habitantes) }\end{array}$} \\
\hline & $1991 / 2000$ & $2000 / 2010$ & $1991 / 2000$ & $2000 / 2010$ \\
\hline Estado de SP & 147.443 & 47.265 & 4,31 & 1,21 \\
\hline RMSP & 24.399 & -29.968 & 1,47 & $-1,60$ \\
\hline RMBS & 13.115 & 5.017 & 9,75 & 3,20 \\
\hline Bertioga & 1.716 & 1.120 & 83,55 & 29,01 \\
\hline Cubatão & 227 & -336 & 2,28 & $-2,96$ \\
\hline Guarujá & 2.314 & -657 & 9,78 & $-2,37$ \\
\hline Itanhaém & 2.107 & 746 & 35,92 & 9,40 \\
\hline Mongaguá & 1.480 & 782 & 55,14 & 19,29 \\
\hline Peruíbe & 1.389 & 168 & 33,11 & 3,03 \\
\hline Praia Grande & 5.819 & 4.674 & 36,93 & 20,58 \\
\hline Santos & -2.198 & -1.349 & $-5,26$ & $-3,22$ \\
\hline São Vicente & 261 & -132 & 0,91 & $-0,41$ \\
\hline
\end{tabular}

Fonte: IBGE. Censo demográfico / SEADE (2010).

Entre os anos 2000 e 2010, há uma crescente migração intrametropolitana, como uma "força centrífuga", que parte de Santos em direção à periferia metropolitana, em virtude de dois fatores: o preço do solo e o custo de vida mais baixo. Os municípios de Bertioga e Praia Grande aumentaram significativamente suas proporções de residentes neste período. 
Essa região abriga o maior porto em volume de comercialização da América Latina e, conforme apresentado na Tabela 1, verifica-se que sua população é superior a 1,6 milhão de habitantes. Com o décimo maior IDH (Índice de Desenvolvimento Humano) das regiões metropolitanas do Brasil, a região se destaca pelos índices elevados de escolaridade, alfabetização, expectativa de vida e PIB (Produto Interno Bruto) per capita, sendo identificada, no Brasil, como uma região de alta qualidade de vida, o que historicamente tem atraído uma migração com perfis etários e socioeconômicos muito diferentes. (IBGE,2010).

\section{URBANIZAÇÃO E TRANSFORMAÇÃO AMBIENTAL DA BAIXADA SANTISTA}

Até meados do século XIX, a economia da região baseava-se na agricultura e na pesca de subsistência, além da atividade portuária, ainda incipiente e não organizada. A partir do início do século XX, a base agrícola e extrativa regional foi sendo paulatinamente substituída pela bananicultura e pela atividade portuária organizada, que passa a ter importância cada vez maior na região e no Estado. Essa atividade sofre grande impulso no final do século XIX, com a implantação da ferrovia ligando a região - mais especificamente o porto ao interior do Estado - fator este que veio a acelerar o processo de urbanização e desenvolvimento econômico.

Inicialmente, as atividades que desencadearam mais fortemente o processo de desenvolvimento econômico regional foram a bananicultura e, posteriormente, o comércio e a exportação de café, através do porto. Essas atividades foram responsáveis pelo crescimento da população urbana de Santos e pelo espalhamento e fixação da população no entorno, especialmente nas áreas onde havia produção de banana visando à exportação, situadas na parte mais ao sul da região. A cultura da banana foi responsável, inclusive, pela extensão da malha ferroviária em direção ao sul da região e do Estado, através do ramal Juquiá, da Estrada de Ferro Sorocabana. (BARROCAS,2013).

Por outro lado, a atividade portuária foi sendo ampliada conforme ocorriam o crescimento das cidades do interior e o avanço da agricultura, especialmente a cultura do café, no planalto paulistano, em direção ao interior. O aumento da produção, o comércio e a exportação do café propiciaram, também, condições para a implantação e extensão das estradas de ferro, para escoamento dos produtos agrícolas e importação e comércio de produtos manufaturados do exterior. 
A proximidade do Porto de Santos com São Paulo - aproximadamente 68 km, entre o principal centro industrial e consumidor de produtos - assim como as propriedades do porto, foram condicionantes significativas do desenvolvimento da própria cidade de São Paulo, bem como de todo o Estado.

A partir da 2a metade do século XX, com a instalação da Refinaria de Petróleo Presidente Bernardes, no município de Cubatão, no sopé da serra do Mar, inicia-se a implantação do ainda hoje importante polo petroquímico e siderúrgico de Cubatão, que também foi o responsável pela atração e fixação de outro fluxo de migrantes e imigrantes. (GONÇALVES, 2006).

No contexto histórico atual, conjuntamente com o Porto de Santos, a economia da região também se encontra fortemente alicerçada no polo industrial de Cubatão, que conta com grandes instalações industriais de base, nos setores petroquímico e siderúrgico, polarizados pela existência da Refinaria de Petróleo Presidente Bernardes e pela Companhia Siderúrgica Paulista - Cosipa, onde se produz o maior percentual de aço utilizado nas indústrias automobilísticas instaladas no Brasil.

A localização desse polo em Cubatão deveu-se, basicamente, aos fatores: disponibilidade energética, localização estratégica e acessibilidade. A disponibilidade energética foi viabilizada pelo aproveitamento dos desníveis topográficos, existentes entre o planalto no alto da serra do Mar e a região litorânea, que se configuram num plano de baixada, com grande disponibilidade energética.

Desde o início do século XX, são aproveitados os potenciais e condições favoráveis à geração de energia elétrica para abastecimento residencial, portuário e industrial da região, como também da Grande São Paulo, com a instalação do complexo hidroelétrico Billings e Henry Borden. A disponibilidade hídrica formada pelos rios que nascem no planalto e descem a vertente da serra, bem como a água resultante do processo de geração de energia que é lançada no canal de fuga da usina, também proporcionaram uma farta oferta de água para uso nos processos industriais. (AFONSO, 2006).

Outro fator de desenvolvimento do polo foi a disponibilidade de transporte, representada pela proximidade do Porto de Santos, que permitia a exportação de produtos e a importação de matéria-prima e equipamentos, bem como o transporte ferroviário que permitia o acesso à capital e, a partir daí, para o interior do país.

Por outro lado, lamentavelmente, ainda hoje, permanece a triste memória dos graves problemas de descontrole da poluição ocorridos na década de 1970 e 1980, com episódios críticos de poluição aérea, que geraram casos de anencefalia, chuva ácida, perda de vegetação e 
escorregamentos na serra; contudo, após volumosos investimentos nos processos e métodos de produção e controle ambiental, a situação foi revertida.

O polo industrial de Cubatão ainda se caracteriza por ser um dos mais importantes do país, mantendo sua atratividade no tripé formado pela disponibilidade de energia - hoje, não mais produzida pela usina Henry Borden, que funciona a plena carga somente em momentos de pico mas pelo sistema interligado de energia elétrica, o gás natural da bacia de Merluza e do petróleo refinado na Refinaria Presidente Bernardes; o transporte rodoviário e ferroviário, bem como pela localização estratégica, que permite a proximidade com o mercado globalizado, representado pelo Porto de Santos, e o acesso fácil ao mercado representado pela cidade e pelo Estado de São Paulo, bem como com os demais mercados do país e do Mercosul. O polo industrial de Cubatão continua a ter sua base na indústria petroquímica e siderúrgica. (GONÇALVES, 2006).

O Porto de Santos - após o grande período de expansão e crescimento físico e de movimentação de cargas, experimentado na primeira metade do século XX, nas décadas de 1980 e 1990, coincidindo com as crises econômicas conjunturais do país, com o processo de estatização do porto e com o final da concessão à Companhia Docas de Santos - passou por um período de reestruturação e concessão das áreas portuárias para empresas privadas, que, de certa forma, tem resultado em sucessivos recordes de movimentação de carga, embora com grande redução de empregos.

Com as concessões de operação para a iniciativa privada, houve um melhor desempenho das cargas movimentadas, com uma significativa redução da massa de trabalhadores na atividade, que passou de, aproximadamente, 16.000, no final da década de 1980, para cerca de 12.600, no final da década de 1990. (GONÇALVES, 2006).

A pujança econômica propiciada pelas atividades portuárias e industriais, aliadas à construção de infraestruturas de energia, abastecimento e acessibilidade à região, ocorridas a partir da segunda metade do século XX - culminando com a construção da segunda pista da Rodovia dos Imigrantes - atraiu uma grande massa de trabalhadores da construção civil que, sem qualificação, findas as obras, se instalaram na região, acomodando-se na indústria da construção civil, principalmente aquela voltada ao turismo de veraneio.

Recentemente, a região da Baixada Santista, com destaque para a sua maior cidade Santos - tem apresentado um crescimento urbano vultuoso que está associado aos investimentos da indústria do petróleo no Brasil. A descoberta de novos campos de exploração do recurso natural 
está atualmente alterando a paisagem e o espaço da área metropolitana, com importantes transformações se refletindo na dinâmica demográfica regional.

\section{CONSIDERAÇÕES FINAIS}

A indústria de transformação da RMBS encontra-se bastante concentrada na produção do polo petroquímico, químico e siderúrgico de Cubatão e, em menor escala, na fabricação de equipamentos de transporte - segmentos que deverão ter expressivo desenvolvimento com o apoio às atividades de exploração de petróleo e gás.

O porto de Santos, o turismo de veraneio e a indústria do polo de Cubatão caracterizaram, até recentemente, a estrutura econômica, a cultura, a urbanização e a paisagem da região. Recentemente, a indústria extrativa vem ganhando espaço, em função da exploração de petróleo e gás, contando com investimentos maciços por parte da Petrobrás e empresas parceiras, em águas profundas da bacia de Santos. Vislumbra-se, portanto, um novo ciclo econômico, trazendo, em seu bojo, diversos impactos sobre a região.

A própria indústria de base de Cubatão, dentro da perspectiva de subsidiar a exploração do petróleo e gás, vem se estruturando para agregar maior valor aos produtos que fabrica. Nessas condições, a Baixada Santista enfrentará o desafio de interiorizar as novas atividades de apoio requeridas pela Petrobrás e empresas parceiras, sem, contudo, descaracterizar o meio ambiente e comprometer as demais atividades econômicas, particularmente, o turismo.

Os ecossistemas costeiros estão constantemente expostos ao risco da degradação ambiental, sob pressão do fluxo de transporte de cargas do Porto de Santos e de seu entorno, da disposição de resíduos e esgotos do Porto e das cidades da região, dos derramamentos de óleo e outras substâncias tóxicas. Some-se a isso, o aumento populacional nos períodos de pico turístico sazonal, em alguns de seus municípios, além da grande massa de trabalhadores da construção civil que se instalou nas encostas e nos manguezais, ou ainda, em áreas periféricas, dada a inviabilidade de construção de habitação popular na zona costeira.

A verticalização e a valorização imobiliária crescentes, aliadas às condições naturais de uma área insular e com falta de espaço físico para a expansão horizontal da área urbana, tem provocado uma intensificação do adensamento urbano no núcleo central da região metropolitana. Com isso, observa-se uma elevação da renda da terra urbana, transformando-a, cada vez mais, em um valor de troca pouco acessível à população de baixa renda. 
Na Baixada Santista, como em todas as áreas urbanas do litoral brasileiro, o preço do solo é alto e as áreas centrais são ocupadas pelas camadas de maior poder aquisitivo; na periferia, se concentram os imóveis de baixo valor imobiliário, próximo às áreas de subemprego ou mais afastados, como os aterros ferroviários e rodoviários, encostas serranas e manguezais, ou ainda, áreas sem interesse imediato para os empreendedores imobiliários - essas terras vêm sendo ocupadas por bairros populares ou por assentamentos espontâneos, não planejados. (AFONSO, 2006).

Do ponto de vista demográfico, dois movimentos contraditórios podem ser observados: se, por um lado, há hoje uma migração de uma parcela da população de alto poder aquisitivo e social para a região, atraída pela oportunidade de desfrutar de uma boa qualidade de vida, associada às novas opções de moradia, lazer e trabalho na região, há uma outra parcela da sociedade - a de menor poder aquisitivo - que vem sendo gradualmente excluída desse espaço metropolitano central. A opção deste segmento da população é migrar para os demais municípios da região metropolitana, como os municípios de São Vicente, Praia Grande e Guarujá, que, forçosamente, também irão passar por um processo de transformação urbana para acolher esses migrantes, que buscam uma renda da terra menor e um custo de vida mais baixo.

Ou seja, as complexas transformações urbanas e demográficas da região irão ocorrer no escopo da lógica social excludente e de fragmentação regional.

Confinada entre o litoral e a Serra do Mar, a região é dotada de complexa relação ambiental, populacional e econômica, reunindo vocações econômicas aparentemente contraditórias, como os complexos portuário e industrial de grande porte e a atividade turística, em meio a reservas e áreas de proteção ambiental.

Retomando nossa questão inicial, acerca das condições de sustentabilidade urbana de uma região, cabe ressaltar que, conforme fartamente explorado pela literatura, a sustentabilidade urbana é definida a partir de um conjunto de prioridades, tais como: superar a pobreza, promover a equidade, melhorar a segurança ambiental e prevenir a degradação, sem gerar externalidades negativas para outras regiões e para as gerações futuras.

A partir disso, prospecta-se para a RMBS um longo trabalho de gestão pela frente, embasado em políticas públicas consistentes, de forma a vencer os aspectos sociais, econômicos e ambientais deficitários, do ponto de vista da sustentabilidade. 


\section{REFERÊNCIAS BIBLIOGRÁFICAS}

ACSERALD, H. (1999). Discursos da sustentabilidade urbana. Revista Brasileira de Estudos Urbanos e Regionais, 1. Rio de Janeiro, ANPUR, 1999.

ALMEIDA, M. H. T. A política social no governo Lula. Novos Estudos CEBRAP, vol.1, São Paulo, 2005.

BARROCAS, R. A dinâmica demográfica recente na Região Metropolitana da Baixada Santista (SP): apontamentos para a discussão da geografia da população em áreas metropolitanas. Encontro de Geógrafos de América Latina. Lima, 2013.

BENKO, G. Economia, espaço e globalização na aurora do século XXI. São Paulo, Hucitec, 1996.

BOYER, R. A teoria da regulação: uma análise crítica. São Paul, Nobel, 1990.

BRAGA, T. M. Sustentabilidade e condições de vida em áreas urbanas: medidas e determinantes em duas regiões metropolitanas brasileiras. Revista Eure Vol. XXXII, Santiago, 2006.

BRENNER, N. New state spaces: urban governance and the rescaling of statehood.

New York, Oxford University Press, 2004.

CETESB. Disponível em: http://www.cetesb.sp.gov.br/agua/aguas-superficiais/35-publicacoes-/relatorios, acesso em 10/03/14.

Environmental Sustainability Index (2002). Disponível em: http://www.ciesin.columbia.edu/indicators/ESI/acesso em 16/03/14.

GOLÇALVES, A. Desenvolvimento econômico da Baixada Santista. Santos, Leopoldianum, 2006.

HOLCMAN, N.M.; LATORRE, M.R.D.O.; SANTOS, J.L.F. Evolução da mortalidade infantil na região metropolitana de São Paulo, 1980-2000. Revista Saúde Pública, v. 38, n. 2, São Paulo, 2004.

Instituto Brasileiro de Geografia e Estatística. Indicadores de desenvolvimento sustentável: Brasil 2004. Brasília: Instituto Brasileiro de Geografia e Estatística, 2004.

JAKOB, Alberto Augusto Eichman. Vetores de expansão urbana e fluxos migratórios na Baixada Santista. In: In VAZQUEZ, Daniel A. (Org.). A questão urbana na Baixada Santista: políticas, vulnerabilidades e desafios para o desenvolvimento. Santos, Editora Leopoldianum, 2012.

MARICATO, E. Indústria da construção e política habitacional. São Paulo, 1984. Tese (Doutorado) Faculdade de Arquitetura e Urbanismo, Universidade de São Paulo.

MARICATO, E. Metrópoles desgovernadas. Estudos avançados. vol.25 no.71 São Paulo Jan./Apr. 2011.Instituto de Estudos Avançados da Universidade de

São Paulo,2011. 
MCGRANAHAN, G. e D. SATTERTHWAITE. The environmental dimensions of sustainable development for cities. Geography, 87, 3, 2002.

MILLER, R.B. Cities from space: potential applications of remote sensing in urban environmental research and policy. Environmental Science\& Policy, 6, 2003.

NOVAES, W. Agenda 21 brasileira: bases para discussão. Brasília: MMA/PNUD, 2000. OBSERVATÓRIO DAS METRÓPOLES. Como Andam as Metrópoles. Disponível em http://www.observatoriodasmetropoles.net. Acesso em 21/03/14.

Portal planalto. Disponível em: http://www2.planalto.gov.br/excluir-historico-nao-seramigrado/plano-nacional-de-saneamento-basico-e-aprovado-com-previsao-de-investimento-de-r508-5-bi-ate-2030. Acesso em: 20/03/14.

PRÜSS-ÜSTÜN, A. et al. Safer water, better health: costs, benefits and sustainability of interventions to protect and promote health. Geneva, World Health Organization, 2008.

REIS FILHO, N.G. Urbanismo no Brasil: séculos XIX-XX. In: ALOMAR, G. Estúdios de história urbana Ibero-americana, Madrid, IEAL, 1987.

ROGERS, R. GUMUCHDIIAN, P. Cidades para um pequeno planeta. Barcelona, Gustavo Gili, 2001.

SALDIVA, P. et al. (Org.) Meio ambiente e saúde, o desafio das metrópoles. São Paulo: Ex-libris, 2010.

SANT'ANNA, A. A., BORÇA Jr., G. R. \& ARAÚJO, P. Q. Mercado de crédito no Brasil: Evolução recente e o papel do BNDES (2004 - 2008)". Revista do BNDES: Rio de Janeiro: BNDES, no 31, jun., 2009.

SCOTT, A. Regions and the world economy: the coming shape of global production, competition, and political order. New York: Oxford University Press, 1998. Sistema Nacional de Informação Sobre Saneamento. Disponível em: http://www.snis.gov.br. Acesso em 20/03/14.

STORPER, M. The regional world: territorial development in a global economy. New York, Guilford Press, 1997.

SWYNGEDOUW, E. Neither global nor local: "glocalization" and the politicas of scale. In: COX, K. R. (Ed.). Spaces of globalization. New York, Guilford Press, 1997.

UN-HABITAT. The state of the world cities. London, Earthscan. 2010.

ZÜNDT, C. Expansão metropolitana, mobilidade espacial e segregação nos anos 90. Núcleo de Estudos Populacionais - Nepo, Unicamp. Disponível em: http://www.nepo.unicamp.br/textos/.../vulnerab_cap_11_pgs_305_336.pdf. acesso em 22/03/14.

VAZQUEZ, D. A. Tendências demográficas e socioeconômicas nos municípios da Baixada Santista. In VAZQUEZ, Daniel A. (Org.). A questão urbana na Baixada Santista: políticas, vulnerabilidades e desafios para o desenvolvimento. Santos, Editora Leopoldianum, 2012. 
Trabalho enviado em 26 setembro de 2014.

Aceito em 09 de outubro de 2014. 